\title{
Improved cephalic index following early cranial vault remodeling in patients with isolated nonsyndromic sagittal synostosis
}

\author{
*Arvid Frostell, MD, PhD, ${ }^{1,2}$ Maryam Haghighi, MD,,2 Jiri Bartek Jr., MD, PhD,1-3 \\ Ulrika Sandvik, MD, PhD, ${ }^{1,2}$ Bengt Gustavsson, MD, ${ }^{1,2}$ Adrian Elmi-Terander, MD, PhD, ${ }^{1,2}$ and \\ Erik Edström, MD, PhD ${ }^{1,2}$ \\ ${ }^{1}$ Department of Neurosurgery, Karolinska University Hospital, Stockholm; ${ }^{2}$ Department of Clinical Neuroscience, Karolinska \\ Institutet, Stockholm, Sweden; and ${ }^{3}$ Department of Neurosurgery, Rigshospitalet, Copenhagen, Denmark
}

\begin{abstract}
OBJECTIVE Isolated nonsyndromic sagittal synostosis (SS) is the most common form of craniosynostosis in children, accounting for approximately $60 \%$ of all craniosynostoses. The typical cranial measurement used to define and follow $\mathrm{SS}$ is the cephalic index $(\mathrm{Cl})$. Several surgical techniques have been suggested, but agreement on type and timing of surgery is lacking. This study aimed to evaluate the authors' institutional experience of surgically treating SS using a modified subtotal cranial vault remodeling technique in a population-based cohort. Special attention was directed toward the effect of patient age at time of surgery on long-term $\mathrm{Cl}$ outcome.
\end{abstract}

METHODS A retrospective analysis was conducted on all patients with isolated nonsyndromic SS who were surgically treated from 2003 to 2011. Data from electronic medical records were gathered. Eighty-two patients with SS were identified, 77 fulfilled inclusion criteria, and 72 had sufficient follow-up data and were included. $\mathrm{Cl}$ during follow-up after surgery was investigated with ANOVA and a linear mixed model.

RESULTS In total, 72 patients were analyzed, consisting of 16 females (22\%) and 56 males (78\%). The mean \pm SD age at surgery was $4.1 \pm 3.1$ months. Blood transfusions were received by $81 \%$ of patients $(26 \%$ intraoperatively, $64 \%$ postoperatively, $9 \%$ both). The mean \pm SD time in the pediatric ICU was $1.1 \pm 0.25$ days, and the mean \pm SD total hospital length of stay was $4.6 \pm 2.0$ days. No patient required reoperation. The mean \pm SD Cl increased from $69 \pm 3$ to $87 \pm 5$ for patients who underwent surgery before 45 days of age. Surgery resulted in a larger increase in $\mathrm{Cl}$ for patients who underwent surgery at a younger age compared with older patients ( $p<0.05$, Tukey's HSD test). In the comparison of patients who underwent surgery before 45 days of age with patients who underwent surgery at 45-90, 90-180, and more than 180 days of age, the linear mixed model estimated a long-term loss of $\mathrm{Cl}$ of $3.0,5.5$, and 7.4 points, respectively.

CONCLUSIONS The modified subtotal cranial vault remodeling technique used in this study significantly improved $\mathrm{Cl}$ in patients with SS. The best results were achieved when surgery was performed early in life.

https://thejns.org/doi/abs/10.3171/2021.1.FOCUS201017

KEYWORDS craniosynostosis; sagittal suture; cranial vault remodeling

$\mathrm{C}$ RANIOSYNOSTOSIS is the premature closure of the cranial sutures in the growing skull of a child. The sutures constitute growth zones in bone, and growth ceases when they close. Consequently, compensatory growth at the nonclosed sutures attempts to provide the brain with sufficient space. This leads to the development of classic skull deformities, reflecting the compensatory growth that characterizes different synostoses. Isolated nonsyndromic sagittal synostosis (SS) is the most common form in children, accounting for approximately $60 \%$ of all craniosynostoses. ${ }^{1}$ The prevalence ranges from 1.8 to 2.5 per 10,000 live births and has a clear male preponderance. ${ }^{1,2}$ Premature fusion of the sagittal suture results in an elongated, narrow skull with frontal bossing and an occipital protuberance. A bony ridge over the suture is often palpable. The term used to describe the clinical features is "scaphocephaly," meaning skiff- or keel-shaped head. ${ }^{3}$ Diagnosis is most often clinical and made in the first few weeks after birth. Neuroradiology can be performed to confirm clinical findings.

ABBREVIATIONS $\mathrm{Cl}=$ cephalic index; $\mathrm{SS}$ = sagittal synostosis .

SUBMITTED November 30, 2020. ACCEPTED January 5, 2021.

INCLUDE WHEN CITING DOI: 10.3171/2021.1.FOCUS201017.

${ }^{*}$ A.F. and M.H. share first authorship of this work. 
Lannelongue performed the first surgery in a patient with SS in the late 19th century, using linear strip craniectomy to remove the offending synostotic bone; since then, several different surgical techniques have been used to correct SS. ${ }^{4}$ A common approach is to perform subtotal cranial vault remodeling before 1 year of age. ${ }^{5}$ More recently, minimally invasive strip craniectomy and endoscope-assisted suturectomy techniques are often utilized to treat SS. Surgery can be accompanied by spring treatment to maintain bony separation. ${ }^{6}$ Postoperative shaping of the skull using helmets has also been advocated. ${ }^{5}$ This context highlights the need for a consensus regarding individual tailoring of these surgical techniques to patients. ${ }^{7-12}$

In addition, agreement is lacking with regard to the timing of surgery and evaluation of surgical results, underscoring the importance of involving patients' families and encouraging shared decision-making. ${ }^{13-17}$

This study aimed to evaluate our institutional experience of using a modified subtotal calvarial vault remodeling technique to surgically treat a population-based cohort of patients with SS. Special attention was paid to the effect of age at time of surgery on surgical outcome. In this study, the cephalic index (CI) (which reflects head shape) was used to assess surgical outcome.

\section{Methods \\ Patients}

The Pediatric Neurosurgical Department of Astrid Lindgren's Children's Hospital at Karolinska University Hospital, Stockholm, Sweden, which is a publicly funded and owned tertiary care center, serves a region of roughly 2 million inhabitants. During the study period, this was the only center in the region accepting referrals for synostosis and the only center with a dedicated children's ICU. All referrals for synostosis were examined by a neurosurgeon.

All patients diagnosed and surgically treated for nonsyndromic SS between January 1, 2003, and December 31,2011 , were retrospectively included in the study. Surgically treated patients were identified with the hospital's surgical management software, Orbit (Every Healthcare Systems). Medical records and imaging data from digital hospital charts were retrospectively reviewed using the health records software TakeCare (CompuGroup Medical Sweden AB).

We excluded patients with combined synostoses, patients who underwent operations with surgical techniques other than cranial vault remodeling, and patients without at least a single preoperative and postoperative measurement of CI.

The study was approved by the regional ethical review board in Stockholm, Sweden, which waived the need for informed consent.

\section{Surgical Procedure}

All surgical procedures were performed under general anesthesia. Prophylactic antibiotics were given at the start of the procedure. Patients were placed prone with the head in a midline position on a soft, horseshoe-shaped headrest. A wavy bicoronal incision extending posteriorly to the ears was used to expose the cranium. Twenty-millimeterwide strip craniectomy was performed to remove the sagittal suture, and the craniotomy cuts were extended anteriorly with wedge-shaped craniectomies (posterior to the coronal suture). Posteriorly, strips were removed anterior to the lambdoid suture, down to the asterion, and then cuts were turned anteriorly toward the coronal suture to create the "beetle wings" that characterize this approach. Greenstick fractures were performed at the bony connection at the attachment of the wing to allow lateral mobilization. If needed, additional radial incisions were performed to correct the occiput. Wounds were closed with resorbable sutures. No drains were used. Blood hemoglobin was monitored vigilantly, and indication for transfusion was $<80$ $\mathrm{g} / \mathrm{L}$ blood hemoglobin or a downward trend approaching $<$ $80 \mathrm{~g} / \mathrm{L}$. Springs were not used in any case. Postoperatively, starting in the recovery room, the child was positioned flat on the back and with the head resting on the occipital bone, to allow gravity alone to improve the widening of the parietal bones and shorten the anteroposterior length. No postoperative helmet therapy was implemented.

\section{Follow-Up}

Routine postoperative follow-up visits were performed at approximately 3 and 12 months. Yearly repeat visits were offered to all patients until the age of 5 years. Any additional visits with recorded CI results were included in the analysis through 6 years of age.

\section{Variables}

Baseline data included patient age, sex, age at surgery, preoperative and postoperative CI, head circumference, and date of diagnosis. Treatment data included operative time, estimated blood loss, and intraoperative and postoperative blood transfusions. Postoperative data included complications, length of hospital stay, CI and head circumference at postoperative follow-ups, and total length of follow-up. Normal values for CI were determined based on data from the literature. ${ }^{18}$

\section{Statistical Analysis}

The cohort was divided into 4 groups based on patient age at surgery: $<45,45-90,91-180$, and $>180$ days of age. Color histograms were made to allow visual inspection of between-group differences in all variables. One-way ANOVA with Tukey's HSD test for post hoc analysis was used for basic comparison of CI outcomes between groups.

A linear regression model and a linear mixed model were applied to estimate the effect of age at time of surgery on long-term outcome measured with CI. Postoperative $\mathrm{CI}$ functioned as the dependent variable, and preoperative CI served as a covariate. Follow-up time was used as a covariate on a logarithmic scale because development of CI over time is approximately log-linear. The linear mixed model was defined with a random intercept but a common slope. Final model selection was performed by keeping significant covariates.

All results were presented as mean \pm SD unless otherwise stated, and statistical significance was defined as $\mathrm{p}<0.05$. 


\section{Nonsyndromic} sagittal synostosis

Other

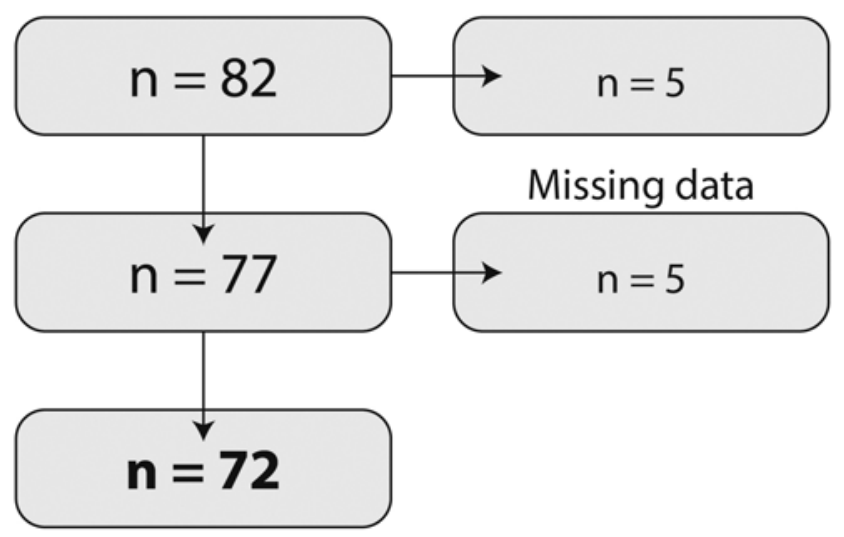

Final cohort

FIG. 1. Flowchart detailing inclusion of patients who underwent surgery for isolated nonsyndromic SS in the final cohort.

All calculations and graphs were performed in R ( $\mathrm{R}$ Foundation for Statistical Computing) using packages "tidyverse," "cowplot," "RColorBrewer," "knitr," "kableExtra," and "nlme." The code is available on request.

\section{Results \\ Study Cohort}

We identified 82 patients who underwent surgery for isolated nonsyndromic SS during the study period of 2003-2011. Of these patients, 5 underwent operations with a different surgical technique than the cranial vault remodeling technique described in this paper: 1 underwent strip craniectomy, 3 underwent barrel-stave osteotomies, and 1 underwent combined cranial vault remodeling and cosmetic correction of the forehead. These 5 patients were excluded from the study, along with 5 patients who lacked follow-up data. In total, 72 patients were defined as the study cohort, as noted in Fig. 1. Of these individuals, 16 $(22 \%)$ were female and $56(78 \%)$ were male. The mean \pm SD age at surgery was $4.1 \pm 3.1$ months. All children were otherwise healthy. The mean \pm SD duration of follow-up after surgery was $27 \pm 15$ months. Baseline characteristics of the study cohort are given in Table 1 and Fig. 2.

\section{Time From Presentation to Surgery}

Data on time from presentation to surgery were available for 56 of 72 patients. The mean \pm SD time from presentation to surgery was $53 \pm 31$ days. Grouping by age at surgery showed that the youngest patients ( $<45$ days) presented at a mean \pm SD age of $8 \pm 8$ days and underwent operations within $28 \pm 7$ days, patients who were 45-90 days old presented at $23 \pm 16$ days and underwent operations within $45 \pm 17$ days, patients who were 90-180 days old presented at $61 \pm 39$ days and underwent operations within $66 \pm 33$ days, and patients who were $>180$ days old presented at $220 \pm 57$ days and underwent operations within $73 \pm 46$ days.

\section{Surgery}

The mean \pm SD surgical time was $100 \pm 31$ minutes. No damage to the dura mater or the sagittal sinus was recorded. The mean blood loss was $29 \pm 23 \mathrm{ml}$, and transfusions were given to $81 \%$ of patients (26\% intraoperatively, $64 \%$ postoperatively, $9 \%$ both). Many infants reached $80 \mathrm{~g} / \mathrm{L}$ hemoglobin with blood loss of only $30 \mathrm{ml}$ in combination with intraoperative hemodilution with intravenous fluids. The mean \pm SD time in the pediatric ICU was $1.1 \pm 0.25$ days, and the mean \pm SD total hospital length of stay was $4.6 \pm 2.0$ days. No patient required reoperation.

\section{Complications}

In total, 2 patients (3\%) had complications. One patient had postoperative subgaleal hematoma that did not require surgical intervention and was treated with plasma and vitamin K. One patient had signs of superficial wound infection with positive culture for Staphylococcus aureus and was successfully treated with antibiotics.

\section{Cephalic Index}

For all included patients, preoperative CI and at least one postoperative value were recorded. Missing data consisted of the lack of early postoperative measurement for 8 patients and long-term measurement for 6 patients. The mean \pm SD number of follow-up measurements was $3.1 \pm 1$.

The mean CI increased in all groups after surgery, but this increase was more pronounced in patients who underwent surgery at a younger age (Table 2). The mean \pm SD CI increased from $69 \pm 3$ to $87 \pm 5$ for patients who underwent surgery before 45 days of age. The corresponding changes were $68 \pm 3$ to $81 \pm 4,69 \pm 4$ to $78 \pm 5$, and 71 \pm 3 to $75 \pm 4$ for patients who were $45-90,91-180$, and $>$

TABLE 1. Baseline and follow-up characteristics

\begin{tabular}{lcccccccc}
\hline $\begin{array}{c}\text { Age Group } \\
\text { (days) }\end{array}$ & $\begin{array}{c}\text { No. of } \\
\text { Patients }\end{array}$ & $\begin{array}{c}\text { No. of } \\
\text { Females/Males }\end{array}$ & $\begin{array}{c}\text { Age at } \\
\text { Op (days) }\end{array}$ & $\begin{array}{c}\text { Weight } \\
\text { at Op (kg) }\end{array}$ & Preop Cl & $\begin{array}{c}\text { Preop Head } \\
\text { Circumference (cm) }\end{array}$ & $\begin{array}{c}\text { No. of } \\
\text { Follow-Ups }\end{array}$ & $\begin{array}{c}\text { Last Follow-Up } \\
\text { (mos) }\end{array}$ \\
\hline$<45$ & 9 & $1 / 8$ & $36 \pm 4$ & $4.5 \pm 0.4$ & $69 \pm 3$ & $39 \pm 1$ & $3 \pm 0.7$ & $24 \pm 15$ \\
\hline $45-90$ & 30 & $9 / 21$ & $70 \pm 14$ & $5.6 \pm 1$ & $68 \pm 3$ & $41 \pm 2$ & $3.2 \pm 1.1$ & $29 \pm 15$ \\
\hline $91-180$ & 19 & $5 / 14$ & $126 \pm 28$ & $6.8 \pm 1$ & $69 \pm 4$ & $44 \pm 1$ & $3.1 \pm 0.9$ & $27 \pm 17$ \\
\hline$>180$ & 14 & $1 / 13$ & $293 \pm 71$ & $9.3 \pm 0.9$ & $71 \pm 5$ & $48 \pm 2$ & $3.2 \pm 1.7$ & $28 \pm 15$ \\
\hline
\end{tabular}

Values are expressed as mean \pm SD unless indicated otherwise. 

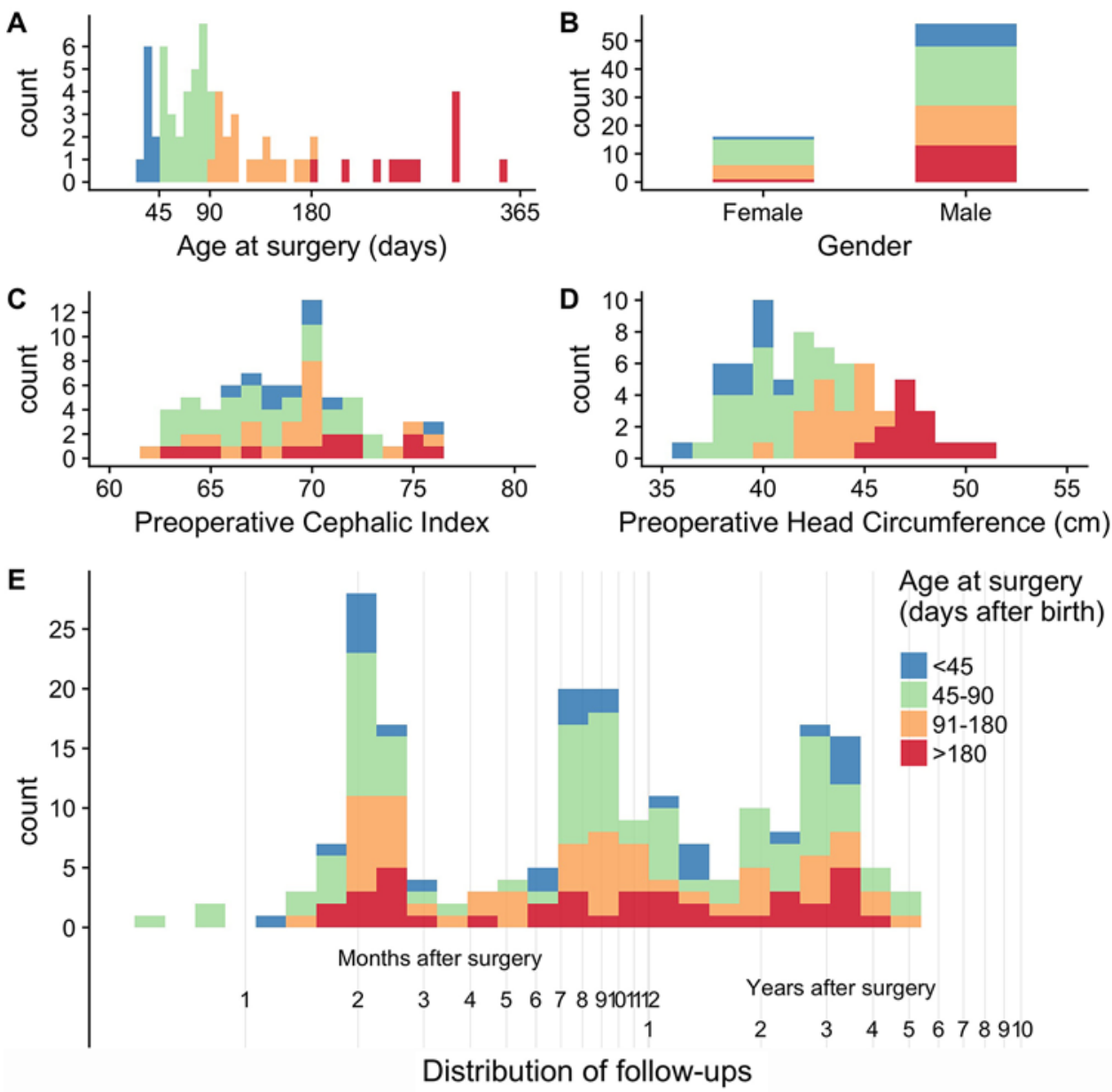

FIG. 2. Age at surgery (A) and sex distributions (B) of the study cohort. Preoperative $\mathrm{Cl}(\mathrm{C})$, preoperative head circumference (D), and length of follow-up (E) are shown for the different age groups.

180 days old, respectively. Between-group differences in postoperative mean CI were statistically significant (Table $3)$. These differences attenuated slightly over time, but at long-term follow-up, the youngest patients $(<45$ days of age at surgery) still had a significantly higher mean CI (78 $\pm 2)$ than the oldest patients ( $>180$ days $)(72 \pm 4)(p<0.05$, Tukey's HSD test).

Figure 3 shows all CI measurements during follow-up, with smoothed means for different groups. The graph illustrates the effect of surgery on CI, as well as normal values for CI based on data from the literature. ${ }^{18}$

\section{Head Circumference}

Head circumference for all groups is shown in Fig. 4. No group deviated from normal values.

\section{Regression Models}

Both linear regression and mixed linear models were fit to the data. The variables that were significant and kept in both models were age at surgery, preoperative CI, and log (age). The linear regression model and the linear mixed model with a random intercept for each individual gave

TABLE 2. Cl and number of missing data points during follow-up

\begin{tabular}{cccccccccc}
\hline \multirow{2}{*}{$\begin{array}{c}\text { Age Group } \\
\text { (days) }\end{array}$} & $\begin{array}{c}\text { No. of } \\
\text { Patients }\end{array}$ & Preop Cl & $\mathrm{Cl}$ & $\begin{array}{c}\text { 1st Follow-Up } \\
\text { (mos) }\end{array}$ & $\begin{array}{c}\text { 1st Follow-Up Missing, } \\
\text { No. of Patients }\end{array}$ & & $\begin{array}{c}\text { Cl at Last } \\
\text { Follow-Up }\end{array}$ & $\begin{array}{c}\text { Last Follow-Up } \\
\text { (mos) }\end{array}$ & $\begin{array}{c}\text { Long-Term Follow-Up } \\
\text { Missing, No. of Patients }\end{array}$ \\
\hline$<45$ & 9 & $69 \pm 3$ & $87 \pm 5$ & $2 \pm 0$ & 0 & $78 \pm 2$ & $24 \pm 15$ & 0 \\
\hline $45-90$ & 30 & $68 \pm 3$ & $81 \pm 4$ & $2 \pm 1$ & 4 & $76 \pm 6$ & $30 \pm 14$ & 3 \\
\hline $91-180$ & 19 & $69 \pm 4$ & $78 \pm 5$ & $2 \pm 1$ & 2 & $74 \pm 5$ & $31 \pm 15$ & 3 \\
\hline$>180$ & 14 & $71 \pm 5$ & $75 \pm 4$ & $2 \pm 1$ & 2 & $72 \pm 4$ & $30 \pm 14$ & 1 \\
\hline
\end{tabular}

Values are expressed as mean $\pm \mathrm{SD}$ unless indicated otherwise. 
TABLE 3. Between-group comparison of Cls during follow-up

\begin{tabular}{|c|c|c|c|c|c|c|}
\hline \multirow{2}{*}{$\begin{array}{c}\text { Age Group Comparison } \\
\text { (days) }\end{array}$} & \multicolumn{2}{|l|}{ Preop } & \multicolumn{2}{|l|}{ Postop } & \multicolumn{2}{|l|}{ Long Term } \\
\hline & Difference in Mean $\mathrm{Cl}$ & p Value* & Difference in Mean $\mathrm{Cl}$ & p Value* & Difference in Mean $\mathrm{Cl}$ & $p$ Value* \\
\hline $45-90$ vs $<45$ & -1.711 & 0.609 & -6.222 & 0.005 & -2.222 & 0.650 \\
\hline $91-180$ vs $<45$ & -0.392 & 0.993 & -9.458 & $<0.001$ & -3.847 & 0.257 \\
\hline$>180$ vs $<45$ & 1.341 & 0.826 & -12.556 & $<0.001$ & -5.761 & 0.046 \\
\hline $91-180$ vs $45-90$ & 1.319 & 0.610 & -3.235 & 0.128 & -1.625 & 0.725 \\
\hline$>180$ vs $45-90$ & 3.052 & 0.057 & -6.333 & 0.001 & -3.538 & 0.158 \\
\hline$>180$ vs $91-180$ & 1.733 & 0.538 & -3.098 & 0.300 & -1.913 & 0.732 \\
\hline
\end{tabular}

Boldface type indicates statistical significance.

${ }^{*}$ Tukey's HSD test.

approximately the same estimates for the effect of surgical timing.

Estimates for the effect of age at surgery reflected the mean differences calculated from the raw data. A progressively lower CI was observed as age at surgery increased. The linear mixed model estimated losses in long-term CI of 3.0, 5.5, and 7.4 points in patients who underwent surgery at 45-90,90-180, and >180 days of age, respectively, when compared with patients who underwent surgery before 45 days of age. See Table 4 for all estimates and $p$ values.

\section{Discussion}

The available literature on the management of SS does not provide a consensus regarding when and how to operate. In this population-based cohort study of patients with SS who were treated with a modified subtotal cranial vault remodeling technique, the effect of age at time of surgery on $\mathrm{CI}$ values was evaluated.
These findings demonstrate a direct correlation between normalization of CI and younger age at surgery. In fact, patients who underwent surgery before 45 days of age showed normalized CI values at their 3-year follow-up.

\section{Surgical Technique}

No definitive evidence favors a certain surgical technique over others for this condition. In a retrospective single-center series, different techniques (H-type, FLAG [foreshortening and lateral expansion of the cranium activated by gravity], endoscopy, etc.) were compared, and the primary outcome measure (improvement of CI) was similar at a mean follow-up of 25.3 months. ${ }^{19}$ It has been proposed that minimally invasive spring-assisted surgery may be advantageous due to shorter operative time, reduced blood loss, shorter ICU time, and shorter hospital stay. However, a 2015 systematic review identified three nonrandomized studies with a high risk of selection bias and could not determine that spring-assisted surgery re-

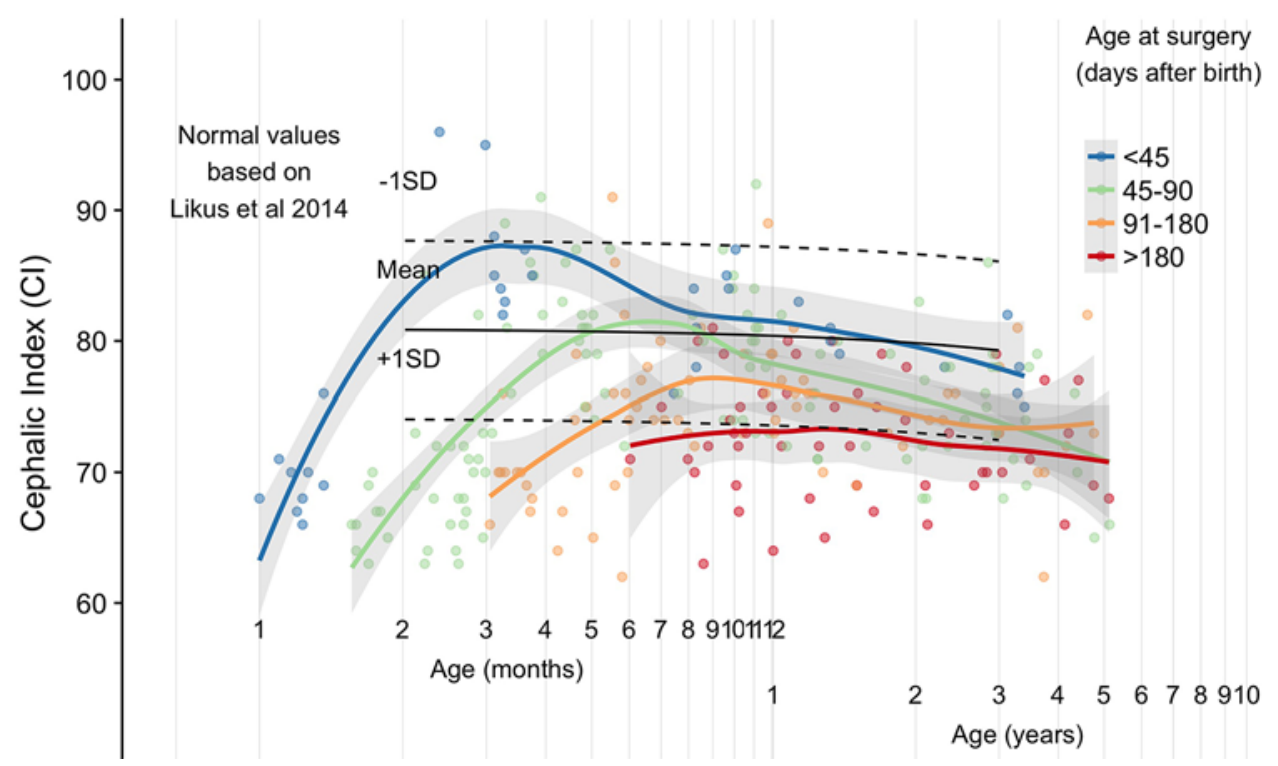

FIG. 3. Changes in $\mathrm{Cl}$ over time are depicted for the groups defined by age at surgery. Note the nonlinear $\mathrm{x}$-axis. Dots represent all individual measurements in the study cohort. Color lines are locally estimated scatterplot smoothing regressions for each group, with $95 \%$ confidence intervals in gray. The difference in $\mathrm{Cl}$ achieved during surgery resulted in better $\mathrm{Cl}$ values on long-term follow-up. Normal $\mathrm{Cl}$ data from the literature ${ }^{18}$ are shown as the black line and dashed lines. 


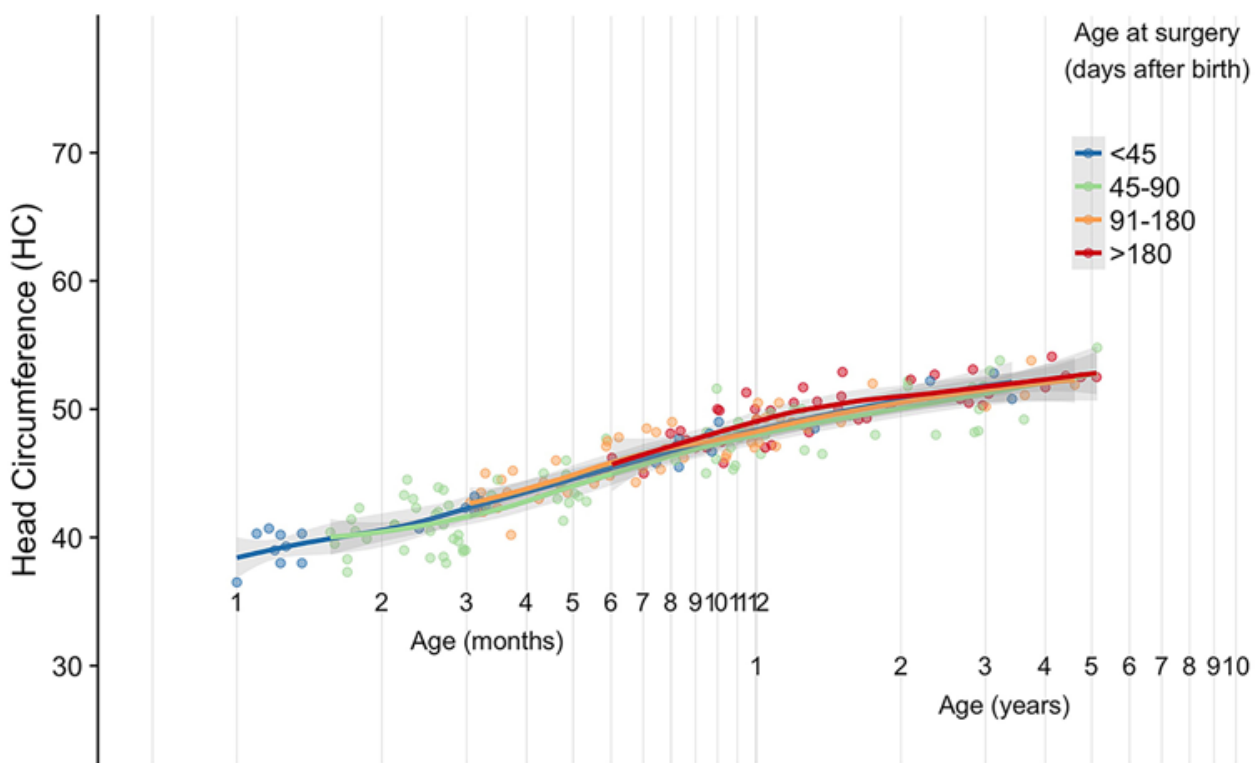

FIG. 4. Head circumference over time is plotted for all groups. No between-group differences or deviations from expected head circumference growth were detected in the study cohort.

sulted in greater improvements in CI compared with other techniques. ${ }^{6}$ Moreover, spring-assisted surgery necessitates follow-up surgery to remove the implanted materials. A 2017 study comparing total cranial vault reconstruction, open sagittal strip craniectomy, and minimally invasive endoscopic strip craniectomy found that endoscopic strip craniectomy had fewer patient deaths and potentially saved costs compared with other techniques. ${ }^{9}$ Decreased morbidity with minimally invasive techniques has also been shown by earlier studies. ${ }^{20}$

In the evaluation of this cohort, we found a median surgical time of 100 minutes, which is comparable to available data on other cranial vault remodeling techniques.9, Blood transfusions were common $(81 \%)$, reflecting the relatively large blood loss of small children undergoing calvarial vault remodeling surgery with extensive saw cuts to the bone. ${ }^{5,21}$ However, no damage to the dura or sagittal sinus was recorded.

Surgical planning for craniofacial surgery may improve greatly with increasing use of augmented and virtual reality surgical navigation technologies. For example, a recent study evaluated virtual surgical planning for pediatric craniofacial surgery and showed workflow benefits when surgery was simulated in advance. ${ }^{22}$

\section{Timing of Surgery}

In 2014, Doumit et al. presented an internet-based questionnaire to 102 craniofacial surgeons in 14 countries on 4 continents. Collected data included preferred timing of surgery. ${ }^{5}$ When presented with a patient with SS younger than 4 months of age, the most common answer was to perform surgery (76\%). However, $24 \%$ of respondents indicated that surgery should be delayed until 6 months of age. Based on the available recommendations, respondents overwhelmingly agreed (97\%) that surgery should be performed before 12 months of age..$^{5,23}$

Investigations of patients with SS at different ages have revealed the natural history of the disease. As in healthy children, intracranial volume increases with time..$^{24-26}$ In this cohort, for patients who did not undergo systematic CT investigations, head circumference values were the best proxy for cranial volume and in agreement with these results (Fig. 4).

TABLE 4. Regression models of $\mathrm{Cl}$ during follow-up

\begin{tabular}{|c|c|c|c|c|c|c|c|c|}
\hline \multirow[b]{2}{*}{ Variable } & \multicolumn{4}{|c|}{ Linear Regression } & \multicolumn{4}{|c|}{ Linear Mixed Model } \\
\hline & Estimate & Standard Error & t Value & $\operatorname{Pr}(>|t|)$ & Estimate & Standard Error & t Value & $\operatorname{Pr}(>|t|)$ \\
\hline Intercept & 69.02 & 6.45 & 10.70 & $2.76 \times 10^{-21}$ & 64.84 & 8.72 & 7.43 & $1.42 \times 10^{-11}$ \\
\hline \multicolumn{9}{|l|}{ Age, days } \\
\hline $45-90$ vs $<45$ & -3.21 & 0.96 & -3.32 & $1.06 \times 10^{-3}$ & -3.09 & 1.39 & -2.22 & $3.01 \times 10^{-2}$ \\
\hline $91-180$ vs $<45$ & -5.32 & 1.03 & -5.15 & $6.50 \times 10^{-7}$ & -5.48 & 1.48 & -3.70 & $4.30 \times 10^{-4}$ \\
\hline$>180$ vs $<45$ & -7.11 & 1.14 & -6.25 & $2.57 \times 10^{-9}$ & -7.43 & 1.58 & -4.70 & $1.36 \times 10^{-5}$ \\
\hline Preop Cl & 0.47 & 0.09 & 5.41 & $1.85 \times 10^{-7}$ & 0.48 & 0.12 & 3.95 & $1.93 \times 10^{-4}$ \\
\hline Log (age in days) & -3.28 & 0.37 & -8.82 & $6.66 \times 10^{-16}$ & -2.77 & 0.26 & -10.74 & $1.68 \times 10^{-9}$ \\
\hline
\end{tabular}


However, development studies of neurological function at different ages affirm that delay in surgical timing has detrimental effects on neurological outcomes. Patel et al. and Hashim et al. found that patients with SS who underwent surgery before 6 months of age had higher intellectual performance (intelligence quotient testing) and, more importantly, higher achievement test scores in school and fewer learning disabilities compared with patients who underwent surgery after 6 months of age. . $^{27,28}$

A retrospective study that evaluated 46 cases of minimally invasive strip craniectomy with 1-year postoperative follow-up showed significantly better correction rates in the youngest patients. The mean age at surgery was 3.1 months, and the optimal timing for intervention was 6 weeks of age (i.e., the earliest the procedure was performed) ${ }^{14}$ Another study of 88 patients who underwent spring-mediated surgery, at a median age of 3.3 months, showed an improvement in median preoperative CI from 69 to 76 at 5 years. Patient age at the time of spring placement and change in CI were inversely related $(\mathrm{p}<0.005)$. The authors maintained that surgery should be performed at 2.5 to 4 months of age..$^{15}$ In conflict with these suggestions, Utria et al. evaluated a large series of 413 patients, and those who underwent surgery before 6 months of age had increased odds of requiring major surgical revisions. ${ }^{16}$ However, no reoperations were identified in our study cohort.

Due to large differences in the management of craniosynostosis between surgeons and centers, a synostosis research group was recently created to study different practice patterns, reduce variation, and contribute multicenter data on the management of children with craniosynostosis. $^{29}$

\section{Limitations}

The conclusions of this study regarding the effect of surgical timing on CI outcomes are most limited by the retrospective design and possible nonrandom allocation of patients to groups based on age at surgery. Therefore, generalization of these findings to other populations should be done with caution. As is typical for clinical data sets, ours contains variations in follow-up times and frequencies. We propose that the chosen statistical method, a linear mixed model, compensates for this variation to some extent. Nonetheless, a possible bias may exist between those who need and those who request follow-up, and statistical methodology cannot compensate for this.

CI values were used because they are the typical clinical measure of skull shape and comparable between studies. However, recent studies have suggested the value of using 3D CT to assess patient head shape because it may more accurately reflect cosmetic outcomes. ${ }^{30,31}$

\section{Conclusions}

The results of the current study from a populationbased cohort who underwent surgery with a modified subtotal cranial vault remodeling technique demonstrate a strong correlation between age at surgery and outcome as measured by CI. Assuming that pediatric critical care resources are available, we conclude that surgery at an early age is safe and leads to improved CI outcomes in patients with isolated nonsyndromic SS.

\section{References}

1. Chatterjee JS, Mahmoud M, Karthikeyan S, et al. Referral pattern and surgical outcome of sagittal synostosis. J Plast Reconstr Aesthet Surg. 2009;62(2):211-215.

2. Massimi L, Caldarelli M, Tamburrini G, et al. Isolated sagittal craniosynostosis: definition, classification, and surgical indications. Childs Nerv Syst. 2012;28(9):1311-1317.

3. Frassanito P, Di Rocco C. Depicting cranial sutures: a travel into the history. Childs Nerv Syst. 2011;27(8):1181-1183.

4. Epstein N, Epstein F, Newman G. Total vertex craniectomy for the treatment of scaphocephaly. Childs Brain. 1982;9(5): 309-316.

5. Doumit GD, Papay FA, Moores N, Zins JE. Management of sagittal synostosis: a solution to equipoise. J Craniofac Surg. 2014;25(4):1260-1265.

6. Maltese G, Fischer S, Strandell A, et al. Spring-assisted surgery in the treatment of sagittal synostosis: a systematic review. J Plast Surg Hand Surg. 2015;49(3):177-182.

7. Gerety PA, Basta MN, Fischer JP, Taylor JA. Operative management of nonsyndromic sagittal synostosis: a head-to-head meta-analysis of outcomes comparing 3 techniques. J Craniofac Surg. 2015;26(4):1251-1257.

8. Taylor JA, Maugans TA. Comparison of spring-mediated cranioplasty to minimally invasive strip craniectomy and barrel staving for early treatment of sagittal craniosynostosis. J Craniofac Surg. 2011;22(4):1225-1229.

9. Garber ST, Karsy M, Kestle JRW, et al. Comparing outcomes and cost of 3 surgical treatments for sagittal synostosis: a retrospective study including procedure-related cost analysis. Neurosurgery. 2017;81(4):680-687.

10. Driessen C, Mathijssen I, van Veelen ML. Update on treatment of sagittal synostosis: what can we learn from the 16th Congress of the International Society of Craniofacial Surgery? J Craniofac Surg. 2017;28(3):589-590.

11. Governale LS. Craniosynostosis. Pediatr Neurol. 2015;53(5): 394-401.

12. Jane JA Jr, Lin KY, Jane JA Sr. Sagittal synostosis. Neurosurg Focus. 2000;9(3):e3.

13. Bergquist CS, Nauta AC, Selden NR, Kuang AA. Age at the time of surgery and maintenance of head size in nonsyndromic sagittal craniosynostosis. Plast Reconstr Surg. 2016; 137(5):1557-1565.

14. Gociman B, Marengo J, Ying J, et al. Minimally invasive strip craniectomy for sagittal synostosis. J Craniofac Surg. 2012;23(3):825-828.

15. Shakir S, Humphries LS, Kalmar CL, et al. Hope springs eternal: insights into the durability of springs to provide longterm correction of the scaphocephalic head shape. J Craniofac Surg. 2020;31(7):2079-2083.

16. Utria AF, Lopez J, Cho RS, et al. Timing of cranial vault remodeling in nonsyndromic craniosynostosis: a single-institution 30-year experience. J Neurosurg Pediatr. 2016;18(5):629-634.

17. Pfeifauf KD, Said AM, Naidoo SD, et al. Evaluation of the patient-practitioner consultation on surgical treatment options for patients with craniosynostosis. J Craniofac Surg. 2020; 31(5):1186-1190.

18. Likus W, Bajor G, Gruszczyńska K, et al. Cephalic index in the first three years of life: study of children with normal brain development based on computed tomography. Sci World J. 2014;2014:502836.

19. Bradford PS, Ishaque M, Shaffrey E, et al. Evolution of surgical management of sagittal synostosis-a single institution review. J Craniofac Surg. 2021;32(1):155-158.

20. Massimi L, Di Rocco C. Mini-invasive surgical technique for sagittal craniosynostosis. Childs Nerv Syst. 2012;28(9): 1341-1345. 
21. Windh P, Davis C, Sanger C, et al. Spring-assisted cranioplasty vs pi-plasty for sagittal synostosis-a long term followup study. J Craniofac Surg. 2008;19(1):59-64.

22. Kalmar CL, Xu W, Zimmerman CE, et al. Trends in utilization of virtual surgical planning in pediatric craniofacial surgery. J Craniofac Surg. 2020;31(7):1900-1905.

23. Warren SM, Proctor MR, Bartlett SP, et al. Parameters of care for craniosynostosis: craniofacial and neurologic surgery perspectives. Plast Reconstr Surg. 2012;129(3):731-737.

24. Heller JB, Heller MM, Knoll B, et al. Intracranial volume and cephalic index outcomes for total calvarial reconstruction among nonsyndromic sagittal synostosis patients. Plast Reconstr Surg. 2008;121(1):187-195.

25. Posnick JC, Lin KY, Chen P, Armstrong D. Sagittal synostosis: quantitative assessment of presenting deformity and surgical results based on CT scans. Plast Reconstr Surg. 1993; 92(6):1015-1024, 1225-1226.

26. Lee SS, Duncan CC, Knoll BI, Persing JA. Intracranial compartment volume changes in sagittal craniosynostosis patients: influence of comprehensive cranioplasty. Plast Reconstr Surg. 2010;126(1):187-196.

27. Patel A, Yang JF, Hashim PW, et al. The impact of age at surgery on long-term neuropsychological outcomes in sagittal craniosynostosis. Plast Reconstr Surg. 2014;134(4):608e-617e.

28. Hashim PW, Patel A, Yang JF, et al. The effects of wholevault cranioplasty versus strip craniectomy on long-term neuropsychological outcomes in sagittal craniosynostosis. Plast Reconstr Surg. 2014;134(3):491-501.

29. Kestle JRW, Lee A, Anderson RCE, et al. Variation in the management of isolated craniosynostosis: a survey of the Synostosis Research Group. J Neurosurg Pediatr. 2018;22(6): 627-631.
30. Calandrelli R, Pilato F, Massimi L, et al. The unseen third dimension: a novel approach for assessing head shape severity in infants with isolated sagittal synostosis. Childs Nerv Syst. 2019;35(8):1351-1356.

31. Vu GH, Mazzaferro DM, Kalmar CL, et al. Craniometric and volumetric analyses of cranial base and cranial vault differences in patients with nonsyndromic single-suture sagittal craniosynostosis. J Craniofac Surg. 2020;31(4):1010-1014.

\section{Disclosures}

The authors report no conflict of interest concerning the materials or methods used in this study or the findings specified in this paper.

\section{Author Contributions}

Conception and design: all authors. Acquisition of data: Edström, Frostell, Haghighi, Gustavsson. Analysis and interpretation of data: all authors. Drafting the article: Edström, Frostell, Haghighi, Elmi-Terander. Critically revising the article: all authors. Reviewed submitted version of manuscript: all authors. Approved the final version of the manuscript on behalf of all authors: Edström. Statistical analysis: Frostell. Study supervision: Edström, Elmi-Terander.

\section{Correspondence}

Erik Edström: Karolinska University Hospital, Stockholm, Sweden.erik.edstrom@sll.se. 